SANDIA REPORT

SAND2000-8249

Unlimited Release

Printed July 2000



\title{
Effects of Injector Conditions on the Flame Lift-Off Length of DI Diesel Sprays
}

Dennis L. Siebers, Brian S. Higgins

Prepared by

Sandia National Laboratories

Albuquerque, New Mexico 87185 and Livermore, California 94550

Sandia is a multiprogram laboratory operated by Sandia Corporation, a Lockheed Martin Company, for the United States Department of

Energy under Contract DE-AC04-94AL85000.

Approved for public release; further dissemination uniimited. 
Issued by Sandia National Laboratories, operated for the United States Department of Energy by Sandia Corporation.

NOTICE: This report was prepared as an account of work sponsored by an agency of the United States Government. Neither the United States Government, nor any agency thereof, nor any of their employees, nor any of their contractors, subcontractors, or their employees, make any warranty, express or implied, or assume any legal liability or responsibility for the accuracy, completeness, or usefulness of any information, apparatus, product, or process disclosed, or represent that its use would not infringe privately owned rights. Reference herein to any specific commercial product, process, or service by trade name, trademark, manufacturer, or otherwise, does not necessarily constitute or imply its endorsement, recommendation, or favoring by the United States Government, any agency thereof, or any of their contractors or subcontractors. The views and opinions expressed herein do not necessarily state or reflect those of the United States Government, any agency thereof, or any of their contractors.

Printed in the United States of America. This report has been reproduced directly from the best available copy.

Available to DOE and DOE contractors from

Office of Scientific and Technical Information

P.O. Box 62

Oak Ridge, TN 37831

Prices available from (703) 605-6000

Web site: http://www.ntis.gov/ordering.htm

Available to the public from

National Technical Information Service

U.S. Department of Commerce

5285 Port Royal Rd

Springfield, VA 22161

NTIS price codes

Printed copy: A03

Microfiche copy: A01

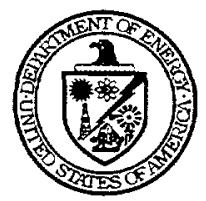




\section{DISCLAIMER}

Portions of this document may be illegible in electronic image products. Images are produced from the best available original document. 


\title{
Effects of Injector Conditions on the Flame Lift-Off Length of DI Diesel Sprays
}

\author{
Dennis L. Siebers and Brian S. Higgins \\ Engine Combustion \& Hydrogen Department \\ Sandia National Laboratories \\ Livermore, California 94550 \\ To be presented at the confernce on: \\ Thermalfluidynamic Processes in Diesel Engines \\ September 14-15, 2000 \\ Valencia, Spain
}

\begin{abstract}
The effects of injection pressure and orifice diameter on the lift-off length of a directinjection (DI) diesel spray (defined as the farthest upstream location of high temperature combustion) were investigated using a natural light emission imaging technique. The lift-off length experiments were conducted in a constant-volume combustion vessel under quiescent, heavy-duty DI diesel engine conditions using a Phillips research grade \#2 diesel fuel.

The results show that natural light emission at $310 \mathrm{~nm}$ provides an excellent marker of the lift-off length. At this location, natural light emission at $310 \mathrm{~nm}$ is dominated by $\mathrm{OH}$ chemiluminescence generated by high-temperature combustion chemistry. Lift-off lengths determined from images of natural light emission at $310 \mathrm{~nm}$ show that as either injection pressure (i.e., injection velocity) or orifice diameter increase, the lift-off length increases. The observed lift-off length increase was linearly dependent on injection velocity, the same dependency as previously noted for gas jets. The lift-off length increase with increasing orifice diameter, however, is different than the independence of lift-off length on orifice diameter noted for gas jets

An important overall observation was made by considering the lift-off length data in conjunction with data from recent investigations of liquid-phase fuel penetration and spray development. The combined data suggests that a systematic evolution of the relationship and interaction between various processes in a DI diesel spray has been occurring over time, as injection pressures have been increased and orifice diameters reduced as part of efforts to meet emissions regulations. The trends observed may eventually help explain effects of parameters such as injection pressure and orifice diameter on emissions.
\end{abstract}




\section{Introduction}

Once the autoignition phase is over, the flame on a high-pressure, direct-injection (DI) diesel fuel spray stabilizes at a quasisteady location significantly downstream of the injector tip. The distance from the injector tip to this initial flame location is referred to as the "lift-off" length (or height) in turbulent diffusion flame research. The lift-off length changes in response to changes in engine and injector parameters. In addition, instantaneous fluctuations about the quasisteady mean lift-off length occur as a result of turbulence. The lifted flame phenomenon is visible in numerous images of DI diesel sprays in the literature [e.g., 1-3], but only a few direct measurements of the lift-off length have been made under diesel conditions $[4,5]$.

The flame stabilization process at the lift-off length is determined by a complex set of interactions between turbulent fluid mechanic and flame chemistry processes. Historically, several competing theories have been proposed to explain this flame stabilization process $[6,7]$, some of which are being challenged by recent atmospheric pressure gas jet research [7]. At the macroscopic level, research is now suggesting that the flame stabilization occurs along the stoichiometric mixture contour, at a location where a balance exists between the convective flow downstream in the jet and turbulent flame propagation upstream (possibly involving triple flames).

While many of the details of the flame stabilization process are not yet agreed upon, there is growing evidence to suggest that flame lift-off length plays a significant role in DI diesel combustion and emissions formation processes, making lift-off length of significant practical importance to diesel engines. The effect of lift-off length on diesel combustion occurs as a result of premixing of injected fuel and entrained air upstream of the lift-off length. Recent modeling by Chomiak and Karlsson [8] and optical measurements by Dec and coworkers [9] suggest that this premixed fuel and air reacts in a rich, distributed reaction zone located in the central region of the spray, just downstream of the lift-off length. ${ }^{1}$ For a moderate-load engine condition, estimates of air entrainment based on our current understanding of spray entrainment [10] indicate that enough air is entrained upstream of the lift-off length to burn up to $20 \%$ of the injected fuel. As a result, the central reaction zone is likely to generate a significant local heat release and a high-temperature product gas, rich in unburned and/or partially reacted fuel. This product gas becomes the "fuel" for the remaining diesel combustion processes downstream, making the upstream air entrainment and the ensuing rich combustion in the central reaction zone of critical importance to all remaining downstream combustion processes. Moreover, the product gas is ideal for forming soot. Dec's conceptual model of diesel combustion [9] has soot formation beginning in the product gas of the central reaction zone, with soot growth occurring as the gas is transported downstream in the penetrating, reacting fuel jet. This soot formation concept is supported by a recent modeling effort, coupling a phenomenological spray model with detailed chemical kinetic modeling [11].

The discussion above implies that lift-off length, which defines the amount of air entrainment and fuel/air premixing that occurs upstream of any combustion in a DI diesel spray, plays a pivotal role in diesel combustion and emission formation processes, especially soot formation processes. However, our understanding of how various parameters affect flame liftoff under diesel conditions is limited. The only information available on diesel spray flame lift-

\footnotetext{
${ }^{\prime}$ Chomiak and Karlsson [8] suggest that this central reaction zone is a rich branch of a triple flame, while Dec [9] hypothesizes a standing, rich premixed flame.
} 
off must largely be inferred from images of visible luminosity in literature, which do not accurately reflect the farthest upstream location of combustion.

The goal of this paper is to present a natural light emission imaging technique for measuring lift-off length, as well as the first systematic investigation of the effects of injection pressure and orifice diameter on flame lift-off length for DI diesel sprays. The results were obtained as part of an on going experimental examination of flame lift-off over a wide range of quiescent DI diesel conditions.

The lift-off length data presented in the paper are also considered in combination with data from other recent investigations of liquid-phase fuel penetration and spray development. Taken together, the data provide significant new insight on the relationship and interaction between various processes in a DI diesel spray. The picture developed from the combined data suggests that the DI diesel combustion and emission processes have been evolving as injection pressure has been gradually increased over time to meet emissions regulations. The trends observed are trends that models being developed for DI diesel combustion must capture to accurately model diesel combustion and emissions processes.

(Note: Consideration of the effects of cross-flows, i.e., swirl and squish, on flame lift-off is beyond the scope of this paper. An investigation of the impact of these parameters on lift-off under diesel conditions is needed.)

\section{Experimental Apparatus and Procedure}

The experiments were conducted under simulated, diesel engine conditions in a constantvolume combustion vessel. Figure 1 shows a schematic cross-section of the combustion vessel. This combustion vessel is capable of handling gas pressures more than a factor-of-two higher than those found in current-technology diesel engines and can be used to simulate a wide range of in-cylinder thermodynamic conditions, including conditions in proposed advanced, highpower-density automotive and heavy-duty diesel engines.

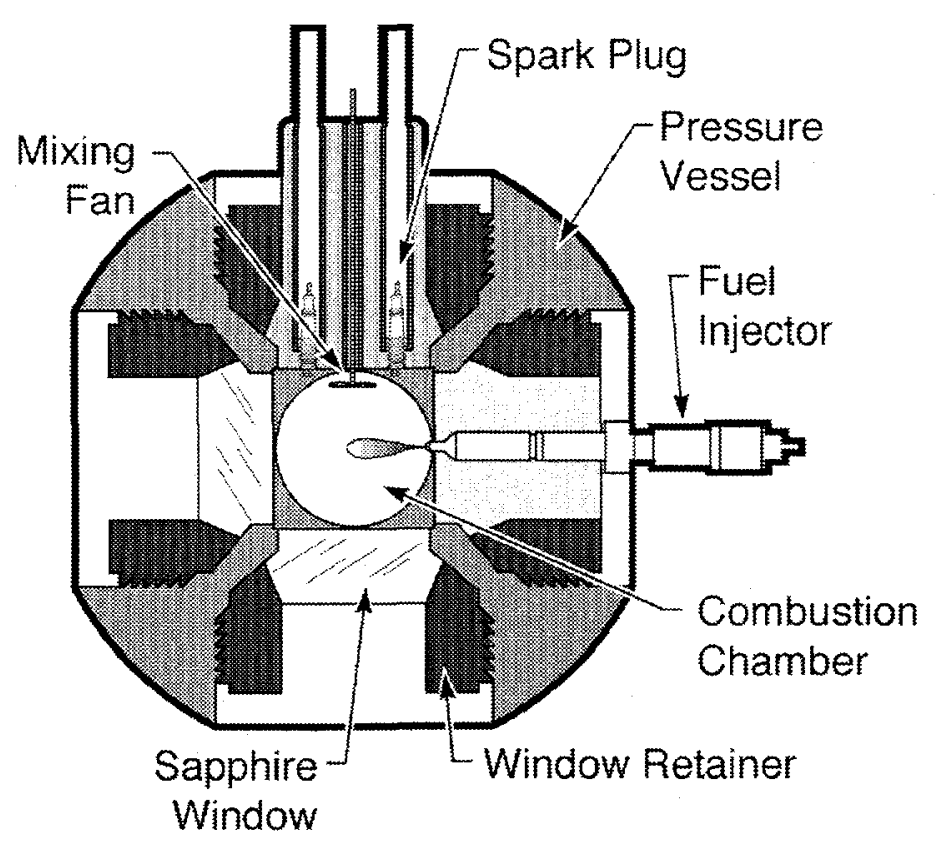

Figure 1. Schematic cross-section of the combustion vessel. 
The combustion vessel has a cubical combustion chamber with a characteristic dimension of $108 \mathrm{~mm}$. Each side of this combustion chamber has a round port with a diameter of $105 \mathrm{~mm}$. The fuel injector is mounted in the right side port in a metal insert. The optical access is provided by sapphire windows located in four of the ports. Two windows are in the left side and the bottom ports of the vessel as shown in the figure. The other two windows form the front and back sides of the combustion chamber in the schematic. The sapphire windows permit full optical access into the vessel for optical diagnostics requiring either line-of-sight or orthogonal optical access. The top port in the vessel contains two spark plugs and a mixing fan mounted in a metal insert. The spark plugs and mixing fan are used in the diesel simulation as discussed later. (More detailed discussions concerning the spark plugs and the fan are presented in Refs. [12-14]).

The fuel injector used was an electronically-controlled, common-rail, solenoid-activated injector capable of an injection duration from a fraction of a millisecond to several milliseconds. This injector opened and closed rapidly $(<100 \mu \mathrm{s})$ and had a constant injection rate throughout the injection period, resulting in a top hat injection rate profile. Tips used on the injector had a single orifice in line with the central axis of the injector. (A more detailed description of the fuel injector and tips can be found in Refs. $[10,12,13]$.)

The experimental procedure used to simulate diesel-fuel injection and combustion processes in a constant-volume combustion vessel was developed previously [12-16] and is illustrated by the pressure history in Fig. 2. To summarize, the procedure is started by filling the vessel to a specified density with a premixed, combustible-gas mixture (occurs prior to time zero in Fig. 2). This mixture is then ignited with the spark plugs shown in Fig. 1 and burned (the pressure-rise at approximately 0.1 seconds in Fig. 2), creating a high-temperature, high-pressure environment in the vessel. As the products of this burn cool over a relatively long time due to heat transfer to the vessel walls (between 0.15 and 1.6 seconds in Fig. 2), the vessel pressure slowly decreases. When the desired pressure is reached, the diesel-fuel injector is triggered and the diesel fuel injection, autoignition and combustion process ensues as indicated by the pressure-rise at a time of 1.65 seconds in Fig. 2.

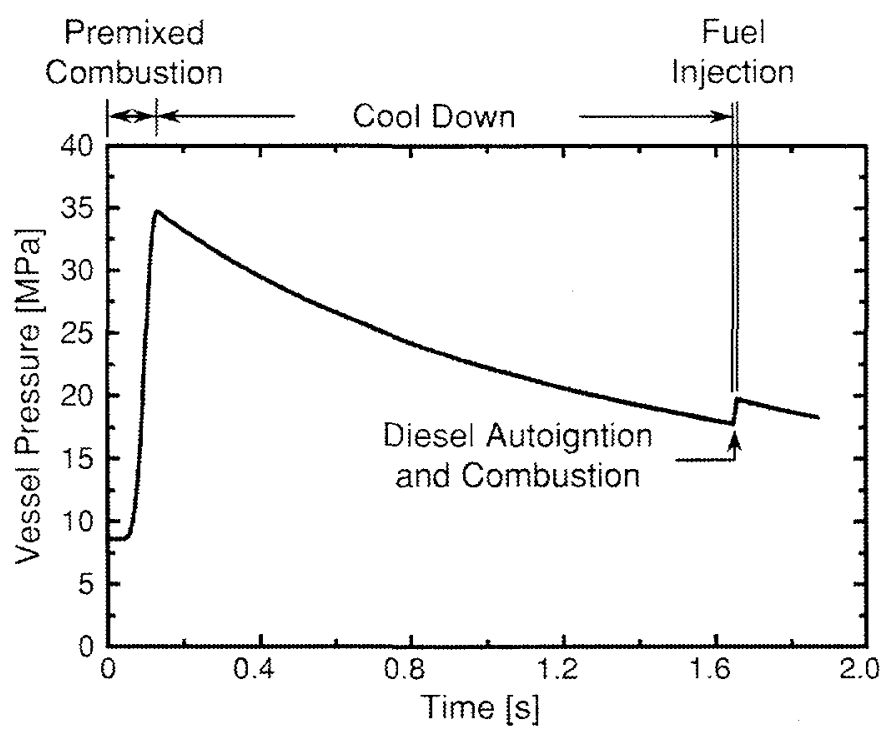

Figure 2. Pressure history in the vessel, illustrating the diesel simulation procedure. 
The temperature, density, and composition of the ambient gas in the vessel at the time of diesel-fuel injection can be varied widely with this simulation procedure. Temperature can be varied from 600 to $1400 \mathrm{~K}$ and density from 3.6 to $60 \mathrm{~kg} / \mathrm{m}^{3}$. The ambient composition is determined by the composition of the combustible-gas mixture burned to create the highpressure/temperature environment in the vessel. For these experiments, a combustible-gas mixture whose product composition simulated air was used. The combustible-gas mixture was composed of $68.1 \% \mathrm{~N}_{2}, 28.4 \% \mathrm{O}_{2}, 3.0 \% \mathrm{C}_{2} \mathrm{H}_{2}$, and $0.5 \% \mathrm{H}_{2}$ (by volume). The combustion products of this mixture had a molecular weight of 29.47 , which is close to the molecular weight of air, and a composition of $21.0 \% \mathrm{O}_{2}, 69.3 \% \mathrm{~N}_{2}, 6.1 \% \mathrm{CO}_{2}$, and $3.6 \% \mathrm{H}_{2} \mathrm{O}$ (by volume).

Throughout an experiment the mixing fan at the top of the combustion chamber (see Fig. 1) is run to maintain a uniform temperature environment in the combustion vessel up to the time of diesel fuel injection $[12,13]$. The gas velocities induced by the fan $(\sim 1 \mathrm{~m} / \mathrm{s})$ are insignificant in comparison to the velocity of the dense liquid fuel jet from the injector (in excess of $250 \mathrm{~m} / \mathrm{s}$ for a these experiments) $[12,13]$. As a result, the gases in the chamber can be considered quiescent relative to the fuel jet.

\section{Experimental Conditions}

Lift-off length data were obtained at an ambient gas temperature of $1000 \mathrm{~K}$ and a gas density of $14.8 \mathrm{~kg} / \mathrm{m}^{3}$. These conditions correspond to the thermodynamic conditions at topdead-center in a heavy-duty diesel engine operating at a moderate load. The fuel used in the experiments was a Phillips research grade \#2 diesel fuel. The initial fuel temperature was $436 \mathrm{~K}$. Relevant fuel properties are available in Ref. 12.

The range of injection pressure considered in the experiments, expressed in terms of the pressure drop across the injector orifice, was 40 to $185 \mathrm{MPa}$. The two orifices used had diameters of $100 \mu \mathrm{m}$ and $246 \mu \mathrm{m}$. Table 1 lists the discharge coefficient $\left(C_{d}\right)$, the area contraction coefficient $\left(C_{a}\right)$, and the orifice length-to-diameter ratio $(I / d)$ for each orifice. The area contraction coefficient is injection pressure dependent [10]. The injection rate for any experiment is the product of the flow area, the discharge coefficient, and the velocity from Bernoulli's equation. The injection velocity is the product of the velocity from Bernoulli's equation and the ratio $C_{d} / C_{a}$, where the ratio $C_{d} / C_{a}$ is the velocity coefficient [e.g., 10].

The injection duration for each experiment was approximately 5 to $6 \mathrm{~ms}$. However, the duration was not a significant factor in these experiments, since the injection pressure (i.e., injection rate) was nearly constant and the ambient gas conditions changed only slightly during an injection event. The duration was chosen mainly to provide a relatively long time over which to acquire images of the average lift-off length, which fluctuated during an injection as a result of turbulence.

Table 1.Injector tip parameters (see Refs. 10 and 12 for more details).

\begin{tabular}{|c|c|c|c|c|}
\hline \multirow{2}{*}{$\begin{array}{c}\text { Orifice } \\
\text { Diameter } \\
d \\
(\mu \mathrm{m})\end{array}$} & \multirow{2}{*}{$\begin{array}{c}\text { Discharge } \\
\text { Coefficient } \\
C_{d}\end{array}$} & \multicolumn{2}{|c|}{$\begin{array}{c}\text { Area-Contraction } \\
\text { Coefficient }\end{array}$} & \multirow{2}{*}{$\begin{array}{c}\text { Length-to- } \\
\text { Diameter } \\
\qquad / d\end{array}$} \\
\hline & & $\begin{array}{c}C_{a} \\
(72 \mathrm{MPa})\end{array}$ & $\begin{array}{c}\boldsymbol{C}_{a} \\
(138 \mathrm{MPa})\end{array}$ & \\
\hline 100 & 0.80 & 0.91 & 0.86 & 4.0 \\
\hline 246 & 0.78 & 0.89 & 0.81 & 4.2 \\
\hline
\end{tabular}




\section{Diagnostics}

\section{Measurement of Experimental Conditions}

During each experiment, the needle lift, the start of injection, the vessel pressure, and the injection pressure were measured. The injector needle lift was monitored with a Hall-effect sensor. The start of fuel injection was determined by the attenuation of a HeNe laser beam directed across the injector orifice onto a photodiode. The real-time output of the photodiode was used to trigger the acquisition of natural light emission images relative to the start of injection. Also, post-processing of the photodiode signal provided the start of injection and the injection duration.

The vessel pressure was measured with a Kistler, model K-6001, piezoelectric pressure transducer coupled to a Kistler, model 5010, charge amplifier. This pressure transducer was located in a lower corner of the vessel, opposite the injector, and was thermally shielded with a ceramic/mica cover [12]. The fuel injection pressure was measured with a Kistler, model 607L, piezoelectric pressure transducer coupled to a Kistler, model 5010, charge amplifier. The fuel pressure transducer was located just upstream of the injector. No flow restrictions existed between the pressure transducer and the injector orifice once the needle opened [12], thus assuring the measured pressure equaled the pressure at the injector tip.

More details on the diagnostics discussed above, as well as details on other diagnostics used for setting and determining experimental conditions (e.g., temperatures) can be found in Ref. 12.

\section{Natural Light Emission Image Acquisition}

Lift-off lengths were determined from images of spectrally filtered natural light emission from burning diesel sprays acquired with an intensified CCD video camera. The camera and optical setups used to acquire the images are discussed in this section. Details concerning the image analysis are discussed in the Results and Discussion section.

Two image acquisition setups were used for these experiments. Figure 3a shows the base setup used to acquire images for determining the flame lift-off length as a function of injection pressure and orifice diameter. Light emitted by the burning spray through the lower combustion vessel window was reflected with an ultraviolet-enhanced, aluminum mirror, passed through a bandpass filter, centered at $310 \mathrm{~nm}$ with a $10 \mathrm{~nm}$ FWHM, and imaged with a video camera.

The setup in Fig. $3 \mathrm{~b}$ was used for experiments conducted to investigate the sensitivity of the measured lift-off length to the camera intensifier gain and the wavelength of the light collected. Two images were acquired simultaneously for these experiments using a splitter plate and two cameras. The splitter plate was a metal-film, neutral density filter with a quartz substrate that reflected $90 \%$ of the light and transmitted $10 \%$. The light reflected by the splitter plate was passed through one of several narrow bandpass filters ranging from $280 \mathrm{~nm}$ to $695 \mathrm{~nm}$ and imaged with Camera A. The light transmitted through the splitter plate was passed through a bandpass filter, centered at $532 \mathrm{~nm}$ with a $10 \mathrm{~nm}$ FWHM, and was imaged with Camera B.

While the gain of Camera A or the filter in front of Camera A was varied, the setup of Camera B shown in Fig. 3b was held fixed. The lift-off length determined from the images acquired with Camera B were used to separate out the inherent $\pm 7 \%$ injection-to injection variations in lift-off length from changes caused by placing various filters in front of Camera $\mathrm{A}$ or adjusting the gain of Camera A. Independently measuring and accounting for the injection-toinjection variations in the lift-off length minimized the number of experiments required to obtain 
an accurate picture of the effects of the wavelength of the light collected and the camera gain on lift-off length.

The video cameras used were electronically gated, intensified $C C D$ video cameras (Xybion ISG-250) with pixel resolutions of 760 by 480 . The images were digitized with an 8 bit, 512 by 480 pixel resolution frame grabber. A frame-transfer inhibit on each camera allowed the image acquisition to begin any time after the start of injection was detected. The lenses used on the cameras were ultraviolet, transmitting lenses (UV-Nikkor $105-\mathrm{mm}, \mathrm{f} / 4.5$ ). The camera and lens together were sensitive to wavelengths as low as $220 \mathrm{~nm}$.

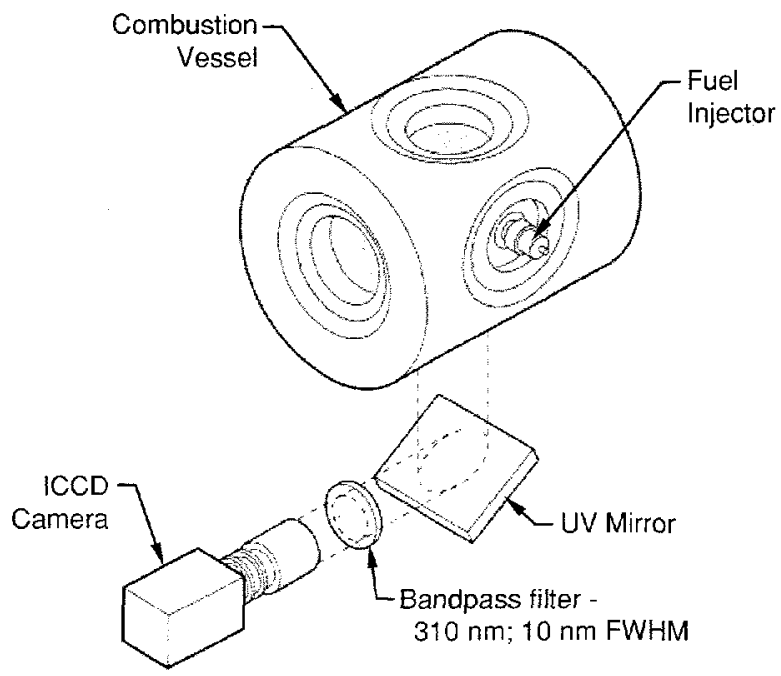

a)

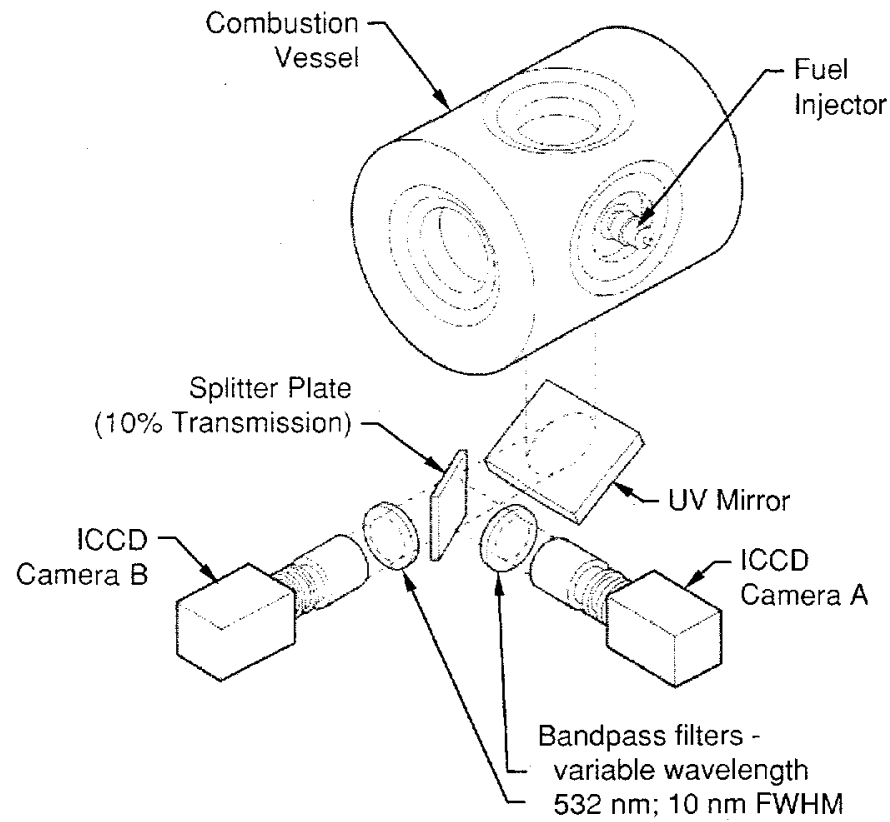

Figure 3. a) Base optical setup used to acquire images for determining lift-off length (top). b) Optical setup used to investigate the effects of camera gain and the wavelength of the imaged light on lift-off length (bottom). 


\section{Results and Discussion}

The technique used to measure the lift-off length and the effects of injection pressure and orifice diameter on the lift-off length are discussed in the first two sections, respectively. The remaining three sections compare the lift-off lengths with previously measured liquid lengths, discuss air entrainment upstream of the lift-off length, and examine the overall implications of the combined lift-off length, liquid length, and air entrainment results for DI diesel sprays.

\section{Measurement of Lift-Off Length}

\section{Time Averaged Images}

Time-averaged, line-of-sight images of natural light emission in the $310 \mathrm{~nm}$ range were acquired and analyzed for lift-off length with the optical setup in Fig. 3a. Light emitted at this wavelength from burning diesel sprays has a strong component of $\mathrm{OH}$ chemiluminescence that marks locations of high-temperature combustion chemistry $[9,18]$, such as at the lift-off length. The most upstream location of $310 \mathrm{~nm}$ light in these images was used to define the flame lift-off length.

The time-averaging was accomplished by gating the camera intensifier open for three milliseconds. The gate was started after the quasisteady lift-off length was established. Timeaveraging allowed turbulent fluctuations in the lift-off length to be averaged, providing an image of the quasisteady mean lift-off length. (Images acquired with a five microsecond gate showed that the turbulent fluctuations from image to image were approximately equal to the half width of the fuel jet at the lift-off length.)

Figure 4 shows an example image of natural light emission at $310 \mathrm{~nm}$ acquired with the $100-\mu \mathrm{m}$ orifice for an injection pressure drop across the orifice of $138 \mathrm{MPa}$ and an ambient-gas temperature and density of $1000 \mathrm{~K}$ and $14.8 \mathrm{~kg} / \mathrm{m}^{3}$. The gray scale in the image is proportional to the collected light intensity. Fuel is injected from left to right. The dot at the left side of the image marks the orifice location.

The image in Fig. 4 shows that light emission at $310 \mathrm{~nm}$ begins at a fairly well defined distance from the injector and extends downstream. The two lobed appearance of the upstream edge of this region is typical. The bright bands extending downstream from the lobes, along the upper and lower edges of each jet, are caused by line-of-sight averaging of the $\mathrm{OH}$ chemiluminescence from the cylindrical diffusion combustion zone that surrounds the jet periphery $[9,18]$. The line-of-sight path length through the diffusion combustion zone is longest where these bright bands appear.

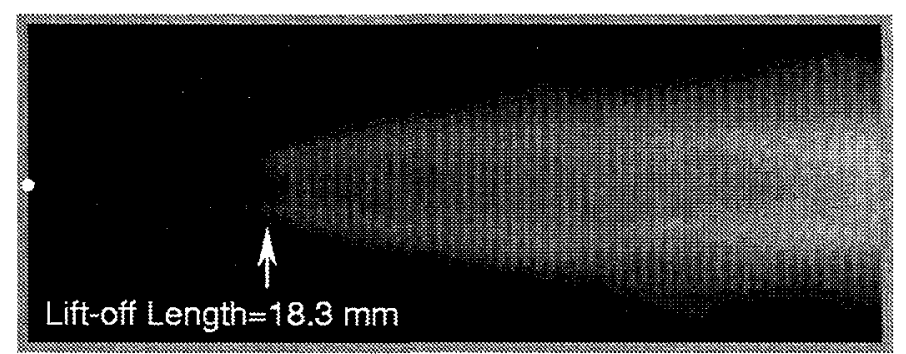

Figure 4. An image of natural light emission at $310 \mathrm{~nm}$. The orifice diameter and orifice pressure drop were $100 \mu \mathrm{m}$ and $138 \mathrm{MPa}$. The gray scale in the image is proportional to the imaged light intensity. Fuel is injected from left to right from an orifice located at the white dot on the left side of the image. The field of view in the image is $63.6 \mathrm{~mm}$. 


\section{Image Analysis for Lift-Off Length}

Image analysis software was developed for determining the lift-off length from an image such as the one shown in Fig. 4. To determine the lift-off length, the distances from the injector to the first axial locations above and below the spray centerline with an intensity greater than a preselected threshold were found. These two distances correspond to the distances from the injector to farthest upstream extent of the upper and lower lobes in light intensity discussed in conjunction with Fig. 4. The average of the two axial distances is defined as the lift-off length. The intensity threshold used was 20 on the 0 to 255 intensity scale of the image, or $8 \%$ of the image intensity range. The lift-off length determined for the image in Fig. 4 is given in the lower left corner of the image. Its location in the image is marked by an arrow.

The lift-off lengths reported in following sections are average lift-off lengths determined from five or more injections (i.e., images). The standard deviation in the lift-off length from injection-to-injection was $\pm 7 \%$. The variations of lift-off length from injection-to-injection are most likely the result of local ambient-gas temperature fluctuations from experiment-toexperiment, which have an rms value of $\pm 30 \mathrm{~K}$ for an ambient gas temperature of $1000 \mathrm{~K}$ [12].

\section{Sensitivity to the Camera Gain and the Threshold}

The lift-off length measurement technique is fairly insensitive to the CCD camera gain and threshold used to define lift-off length. This can be shown with Fig. 5, a semi-logarithmic plot of the maximum relative intensity of the $310 \mathrm{~nm}$ light as a function of the axial distance from the injector. A light intensity range of over two orders of magnitude is shown in the figure. The injection pressure and orifice diameter for data shown were $138 \mathrm{MPa}$ and $100 \mu \mathrm{m}$.

The curve in Fig. 5 was developed from sets of images taken at each of several camera gains with the optical setup in Fig. $3 \mathrm{~b}$ and a $310 \mathrm{~nm}$ filter in front of camera A. As the camera gain was increased, progressively lower levels of natural light emission (at $310 \mathrm{~nm}$ ) were detected further upstream on the spray axis. The average maximum light intensity determined for each image set at each camera gain was scaled based on the calibrated camera gain and compiled to form the curve in Fig. 5, resulting in the segmented appearance of the curve. ${ }^{2}$ In

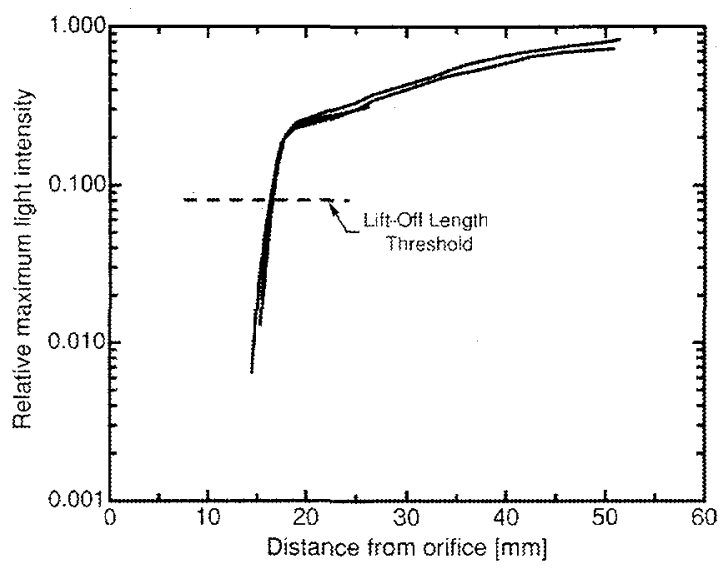

Figure 5. The maximum relative intensity of light at $310 \mathrm{~nm}$ versus the axial distance from the injector orifice. The orifice diameter and orifice pressure drop were $100 \mu \mathrm{m}$ and $138 \mathrm{MPa}$.

\footnotetext{
${ }^{2}$ For higher camera gains, light emission from regions of the spray that would saturate the camera was masked.
} 
addition, a large portion of the $\pm 7 \%$ standard deviation in the axial location of lift-off from injection-to-injection was normalized out using the $532 \mathrm{~nm}$ reference image acquired simultaneously with Camera B in Fig. 3b (see discussion with Fig. 3b).

The important feature of Fig. 5 is the rapid increase in light intensity that begins after an axial distance of approximately $15 \mathrm{~mm}$. The increase in light intensity indicates increased $\mathrm{OH}$ chemiluminescence, which corresponds to increased combustion activity. The threshold used to define lift-off length is represented by the horizontal dashed line at a relative intensity of 0.08 (or 20/255). The lift-off length, defined by the intersection of the dashed line and the curve, is $17 \mathrm{~mm}$. (This value is within the experimental repeatability of the mean lift-off length presented later for this condition in Fig. 9.)

The steep increase in the light intensity at the defined lift-off length indicates that significant changes in the CCD camera gain, or the intensity threshold used to define lift-off length, will have little impact on the measured lift-off length. For example, a $50 \%$ change in either the camera gain or the threshold intensity would have less than a $3 \%$ effect on the measured lift-off length based on the slope of the curve in the vicinity of the lift-off length. This effect is less than the injection-to-injection repeatability of the data.

When investigating the effects of injection pressure and orifice diameter on lift-off length, the camera gain was held fixed at a level that produced images with a maximum light intensity equal to $75 \%$ of the camera saturation level for the baseline condition (an ambient-gas temperature and density of $1000 \mathrm{~K}$ and $14.8 \mathrm{~kg} / \mathrm{m}^{3}$, an injection pressure of $138 \mathrm{MPa}$, and an orifice diameter of $246 \mu \mathrm{m}$ ).

\section{Impact of the Wavelength of the Imaged Light}

The impact of the wavelength of the imaged light on the measured lift-off length was also investigated using the optical setup in Fig. 3b. Images were acquired using the following narrow bandpass filters in front of Camera A in Fig. $3 \mathrm{~b}: 280 \mathrm{~nm}, 310 \mathrm{~nm}, 330 \mathrm{~nm}, 340 \mathrm{~nm}, 434 \mathrm{~nm}$, $532 \mathrm{~nm}$, and $695 \mathrm{~nm}$. Each filter had a $10 \mathrm{~nm}$ FWHM, except for the $695 \mathrm{~nm}$ filter, which had a FWHM of $70 \mathrm{~nm}$. For each filter, the camera gain was adjusted so that the maximum intensity in the image was near $75 \%$ of the saturation level.

Figure 6 is a plot of the maximum relative light intensity measured at various wavelengths as a function of the axial distance from the injector. The curves for each wavelength were developed in the same manner as described for the $310 \mathrm{~nm}$ data shown in Fig. 5. The horizontal dashed line in the figure represents the threshold used to define the lift-off length, the same as in Fig. 5.

Figure 6 shows that lift-off length (defined by the threshold) is independent of wavelength for the two shorter wavelengths, but appears to increase with increasing wavelength above $310 \mathrm{~nm}$. The apparent increase at longer wavelengths, however, can be explained by the limited dynamic range of the camera coupled with the appearance of intense soot incandescence downstream of the lift-off location. Soot formation begins downstream of the lift-off location and progresses in the downstream direction. As a result of the increase in soot in the downstream direction, the natural light emission from the burning spray becomes progressively more dominated downstream by intense broadband soot incandescence. This broadband soot incandescence makes low-level chemiluminescence at wavelengths longer than $310 \mathrm{~nm}$ undetectable in regions with soot present in the spray cross-section. Moreover, it masks lowlevel light emission near the lift-off length where soot does not exist, because the dynamic range of the camera is insufficient to capture both the high intensity soot region downstream and the low-level chemiluminescence region near the lift-off length. 


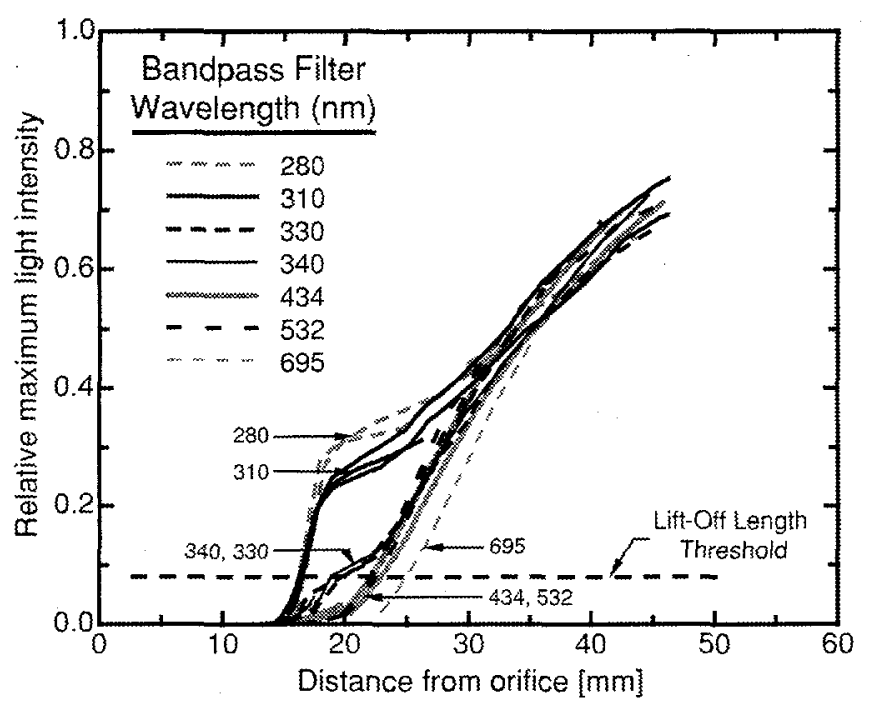

Figure 6. The maximum relative intensity of light at various wavelengths versus the axial distance from the injector orifice. The orifice diameter and orifice pressure drop were $100 \mu \mathrm{m}$ and $138 \mathrm{MPa}$.

The masking effect caused by the dynamic range of the camera explains the trends noted between 15 and $20 \mathrm{~mm}$ in Fig. 6 . For shorter wavelengths ( $280 \mathrm{~nm}$ and $310 \mathrm{~nm}), \mathrm{OH}$ chemiluminescence is strong relative to the soot incandescence, making the $\mathrm{OH}$ chemiluminescence easy to detect even in downstream regions with soot present. ${ }^{3}$ However, for the longer wavelengths ( $330 \mathrm{~nm}$ to $695 \mathrm{~nm}$ ), chemiluminescence from species formed during combustion is considerably weaker than the longer wavelength soot incandescence, thus making the lift-off location more difficult to detect given the limited dynamic range of the camera.

Based on the data in Fig. 6, light emission at $310 \mathrm{~nm}$ was used to measure lift-off lengths. This wavelength provides the best tradeoff between image quality and detectability of the furthest upstream combustion zone in a sooting diesel spray. Use of the $280-\mathrm{nm}$ filter was not considered further because it required operating the camera with the intensifier gain at maximum, resulting in images with lower signal-to-noise levels.

\footnotetext{
${ }^{3}$ Estimates made using the images acquired at the various wavelengths, the calibrated camera gain, and the black body radiation function indicate that $\mathrm{OH}$ chemiluminescence accounts for approximately $50 \%$ of the light emission at $310 \mathrm{~nm}$ in downstream regions with soot. This estimate is in agreement with measurements made with a spectrometer in heavy-duty diesel engine experiments [19].
} 


\section{Injection Pressure and Orifice Diameter Effects on Lift-Off Length}

Images of natural light emission at $310 \mathrm{~nm}$ that illustrate the overall effects of injection pressure and orifice diameter on the lift-off length are shown in Figs. 7 and 8, respectively. The images in Fig. 7 are for the extremes of the injection pressure range considered for the $246 \mu \mathrm{m}$ diameter orifice. The injection pressure is characterized in terms of the pressure drop across the injector orifice $\left(\Delta P_{f}\right.$, the difference between the fuel pressure and the vessel pressure). The measured orifice pressure drop for each image in Fig. 7 is given in the upper left corner. The images in Fig. 8 are for the $100 \mu \mathrm{m}$ and $246 \mu \mathrm{m}$ orifices and an orifice pressure drop of $138 \mathrm{MPa}$. The orifice diameter is given in the upper left corner of each image in Fig. 8.

The images in Fig. 7 clearly show that as the orifice pressure drop increases, the lift-off length increases. Similarly, the images in Fig. 8 show that as orifice diameter increases the liftoff length increases. The lift-off lengths determined from each of these images are given with each image in the lower left corner.

Figure 9 summarizes the effects noted in Figs. 7 and 8 for over 200 images. It is a plot of the lift-off lengths determined for a range of orifice pressure drops, for both orifice diameters. The lift-off lengths in Fig. 9 are plotted versus injection velocity, as is commonly done in the literature for gas jets. The injection velocity is determined from the orifice pressure drop, the orifice coefficients given in Table 1, and Bernoulli's equation. Each data point plotted is the average lift-off length determined from between 5 and 20 images. The bars give the standard deviation in the lift-off length for each condition. As previously noted, the average standard deviation for the data is $\pm 7 \%$.

Figure 9 shows that as the injection velocity increases from $260 \mathrm{~m} / \mathrm{s}$ to $700 \mathrm{~m} / \mathrm{s}$, the liftoff length increases linearly by $8 \mathrm{~mm}$ (or about $50 \%$ ). The linear dependence of lift-off length on injection velocity is the same as that noted previously for gas jets [e.g., 17]. The effect is caused by higher velocities in the spray, which push the initial combustion zone (i.e., the lift-off length) farther downstream.
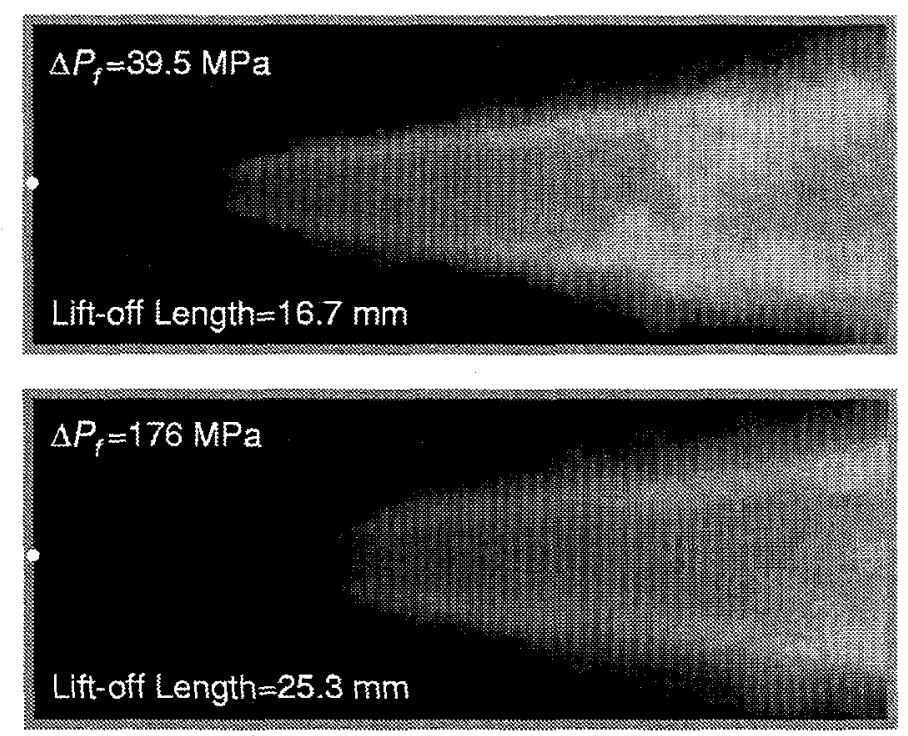

Figure 7. Images of natural light emission at $310 \mathrm{~nm}$ for the extreme injection pressures considered. The top image is for an orifice pressure drop $\left(\Delta P_{f}\right)$ of $39.5 \mathrm{MPa}$. The bottom image is for a $\Delta P_{f}$ of $185 \mathrm{MPa}$. The orifice diameter is $246 \mu \mathrm{m}$. 
As the orifice diameter increases from $100 \mu \mathrm{m}$ to $246 \mu \mathrm{m}$, Fig. 9 shows that the lift-off length increases by $5 \mathrm{~mm}$ (or about 30\%). However, the increase in lift-off length with respect to increasing orifice diameter differs from the trend previously noted for gas jets. For gas jets, it has generally been found that orifice diameter has little impact on lift-off length $[6,7,17]$. The dependence of lift-off length on orifice diameter noted in Fig. 9 is believed to be related to fuel vaporization effects not present in gas jets, as will be discussed more below.
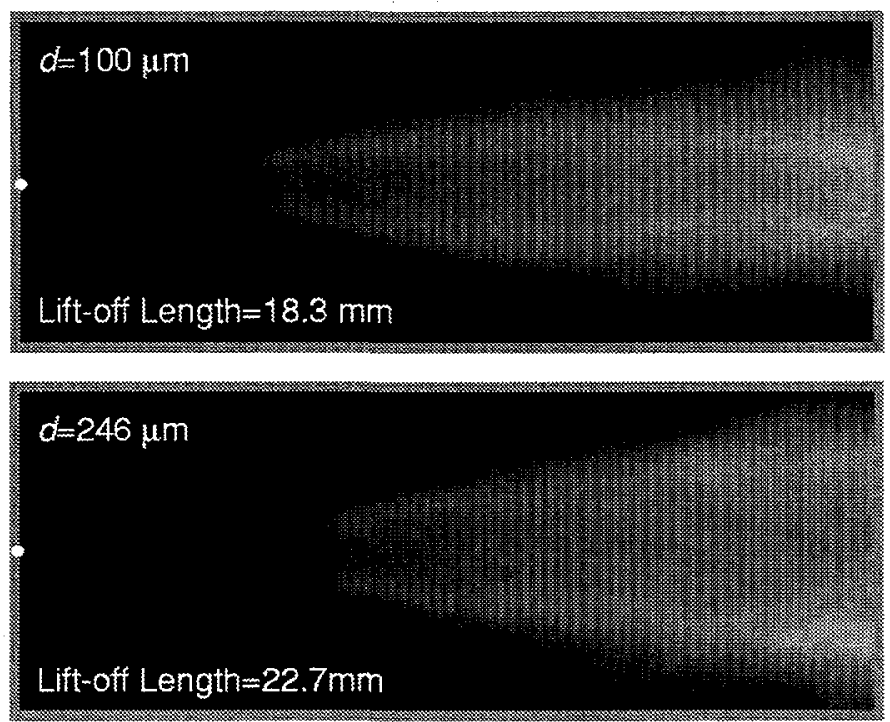

Figure 8. Images of natural light emission at $310 \mathrm{~nm}$ for the $100 \mu \mathrm{m}$ (top) and $246 \mu \mathrm{m}$ (bottom) orifices for an orifice pressure drop of $138 \mathrm{MPa}$.

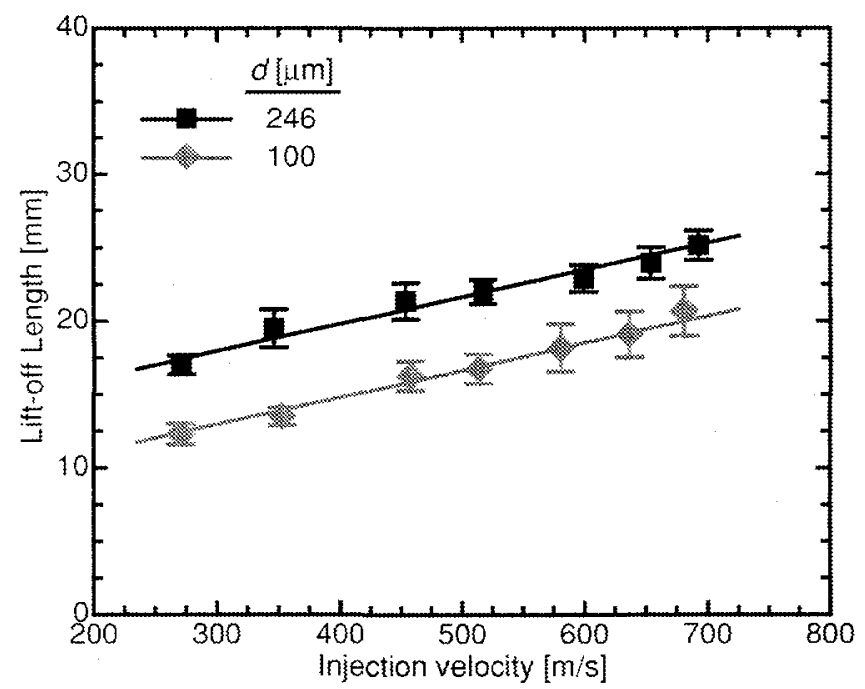

Figure 9. Lift-off length versus the injection velocity for the $100 \mu \mathrm{m}$ and $246 \mu \mathrm{m}$ diameter orifices. Each lift-off length is the average of lift-off lengths determined from between 5 and 20 images for each condition. The standard deviation in the lift-off length for each condition is given by the bars. 


\section{Comparison of Lift-Off and Liquid Lengths}

Previous measurements of liquid-phase fuel penetration in diesel sprays show that the penetration distance of the liquid fuel reaches a maximum, quasisteady length shortly after injection begins [e.g., 12]. This maximum penetration distance is referred to as the liquid length. A comparison of previously measured liquid lengths with the lift-off lengths from this work is made next to show how the relationship between the combustion zones in the spray and the regions of the spray containing liquid-phase fuel change with parameters such as injection pressure and orifice diameter. The changes noted will show how various processes in a diesel spray are evolving as changes in injection pressure and orifice diameter are made as part of efforts to improve engine performance or meet emissions regulations.

The liquid lengths for the orifices, injection pressures, ambient-gas temperature and density, and fuel used in this work were measured and presented in Ref. 12 for non-combusting, vaporizing conditions. A scaling law for liquid length was developed in Ref. 10 which accurately represented the measured liquid length data. Figure 10 compares the liquid lengths based on the scaling law to the measured lift-off lengths shown in Fig. 9. ${ }^{4}$ The lack of dependence of the liquid length on injection velocity (i.e., injection pressure) noted in the figure is a consequence of mixing-limited fuel vaporization discussed in Refs. 10 and 12. The liquid length dependence on orifice diameter is linear.

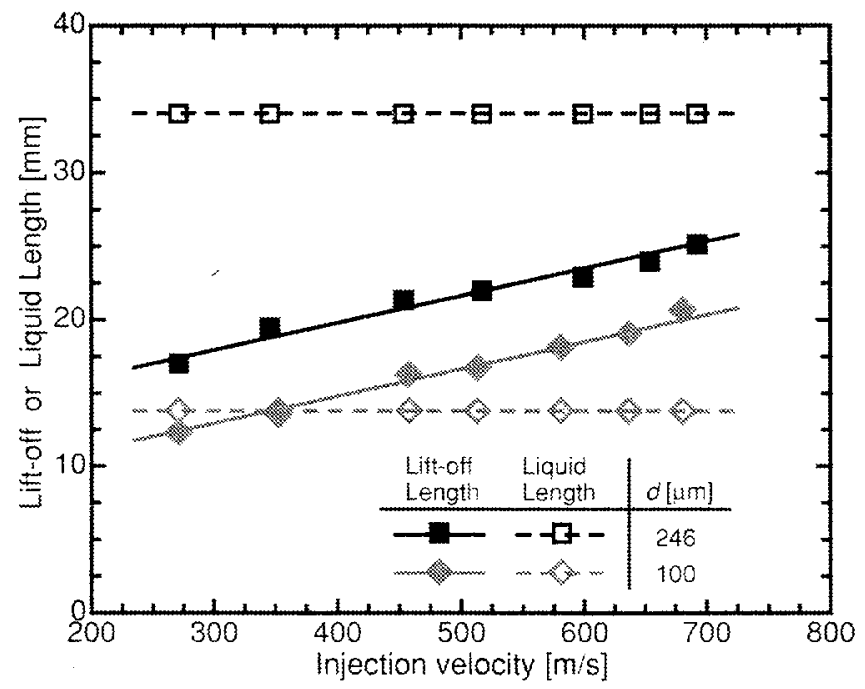

Figure 10. A comparison of lift-off lengths (from Fig. 9) and liquid lengths as a function of injection velocity for the $100 \mu \mathrm{m}$ and $246 \mu \mathrm{m}$ diameter orifices. The liquid length data were obtained from Ref. 10.

\footnotetext{
${ }^{4}$ The liquid lengths shown are for vaporizing sprays. They are only valid for combusting sprays at conditions for which they are shorter than the lift-off length. For combusting sprays with liquid lengths longer than the lift-off length, the additional heat source downstream of the lift-off length is likely to shorten the liquid length in comparison to those shown in Fig. 10. A liquid length longer than a lift-off length only indicates that unvaporized fuel will be transported downstream of the initial combustion zone (i.e., the lift-off length). The longer the liquid length is with respect to the lift-off length, the greater will be the quantity of liquid-phase transported downstream of the lift-off length. The effects of combustion on liquid length for a wide range of injector, engine, and fuel parameters need to be investigated.
} 
Figure 10 shows that for the larger orifice diameter $(246 \mu \mathrm{m})$, the non-combusting, vaporizing liquid length is much longer than the lift-off length measured for the combusting spray. This trend indicates that a significant quantity of liquid-phase fuel will be transported downstream of the initial combustion zone (i.e., the lift-off length). As a result, the center of the spray for the larger orifice diameter is likely to be a very rich, non-combusting mixture of relatively cool, partially vaporized fuel and air. The relationship between the liquid-phase fuel and the initial combustion zone, however, is reversed for the smaller orifice diameter in Fig. 10. For most of the injection velocity range shown for the smaller diameter, the liquid length is shorter than the lift-off length, indicating that only gas-phase fuel is transported downstream of the lift-off length.

Figure 10 clearly shows that the lift-off length and liquid length scale in very different manners with respect to orifice diameter and injection pressure. The result is that the spatial relationship between the various processes involved in diesel combustion will change with these parameters, which in turn, is likely to impact the emissions formation processes. These issues are addressed in more detail in the last section.

\section{Estimated Air Entrainment Upstream of the Lift-Off Length}

As discussed earlier, a change in the lift-off length as a result of a change in injection pressure or orifice diameter will change the amount of air entrained into the spray prior to the initial combustion zone (i.e., the lift-off length). The change in entrained air will in turn alter the average equivalence ratio of the fuel-air mixture entering the central rich, distributed reaction zone that is believed to occur just downstream of the lift-off length $[8,9]$. This will impact the combustion and emissions processes downstream, especially the soot formation process which is believed to begin in the products of this rich reaction zone [9]. The quantity of air entrained upstream of the lift-off length is therefore an important parameter in DI diesel combustion.

The quantity of air entrained prior to the lift-off length can be estimated using the expression for the axial variation of the cross-sectional average equivalence ratio $(\phi)$ in a spray, previously developed by Naber and Siebers [13]. Rearranged, that equivalence ratio relationship gives the air entrained up to the lift-off location as a percentage of the total air required to burn the fuel being injected. This percentage is defined as the percent of stoichiometric air $\left(\zeta_{\mathrm{stt}}\right)$.

$$
\zeta_{\mathrm{st}}(\%)=\frac{10}{3} \cdot\left(\sqrt{1+16 \cdot\left(\frac{L_{\mathrm{o}}}{x^{+}}\right)^{2}}-1\right)=\frac{100}{\phi}
$$

In Eq. (1), $L_{o}$ is lift-off length and $x^{+}$is the characteristic length scale for the spray $[10,13]$ defined by:

$$
x^{+}=\sqrt{\frac{\rho_{f}}{\rho_{a}}} \frac{\sqrt{C_{a}} \cdot d}{0.66 \cdot \tan (\theta / 2)}
$$

In Eq. (2), the term $d$ is the orifice diameter; $C_{a}$ is the area contraction coefficient; $\rho_{f}$ and $\rho_{a}$ are the injected fuel and ambient-gas densities, respectively; and $\theta / 2$ is the measured spreading halfangle of the spray.

Equation (3) from Ref. 10 gives the spray spreading half-angles measured for the two orifices listed in Table 1 as a function of the ambient gas to injected fuel density ratio. 


$$
\tan (\theta / 2)=c \cdot\left[\left(\frac{\rho_{a}}{\rho_{f}}\right)^{0.19}-0.0043 \cdot \sqrt{\frac{\rho_{f}}{\rho_{a}}}\right]
$$

The constant $c$ in Eq. (3) is 0.260 for the $246 \mu \mathrm{m}$ orifice and 0.255 for the $100 \mu \mathrm{m}$ orifice. This equation applies for vaporizing sprays, and therefore applies up to the lift-off length. (See Ref. 10 for more discussion on the spray spreading angles and Eq. (3).)

The percent of stoichiometric air entrained up to the lift-off length, based on Eqs. (1-3), is plotted in Fig. 11 along with the lift-off length data from Fig. 9 for the two orifices. The figure shows that $\zeta_{\text {st }}$ increases linearly with increasing injection velocity. This is due to the linear increase in lift-off length with injection velocity and the dominance of the second term in the square-root term in Eq. (1) for the conditions reported. The trend indicates that one impact of increasing injection pressure is to promote greater premixing of fuel and air upstream of combustion.

Figure 11 also shows that $\zeta_{\text {st }}$ increases with decreasing orifice diameter, even though the lift-off length decreases as orifice diameter decreases. The increase in $\zeta_{\text {st }}$ is due primarily to the strong dependence of air entrainment on orifice diameter seen in Eqs. (1) and (2). The change in $\zeta_{\text {st }}$ due to the decrease in lift-off length with decreasing orifice diameter is a second-order effect. The net result is an increase in $\zeta_{\text {st }}$ that is almost inversely proportional to a reduction in orifice diameter. Clearly, any change in orifice diameter will impact the amount of fuel-air premixing prior to the initial combustion zone. Moreover, the results indicate that on a percentage basis, $\zeta_{\text {st }}$ is 4 to 5 times more sensitive to a change in orifice diameter than a change in orifice pressure drop, making orifice diameter a critical parameter with respect to diesel combustion.

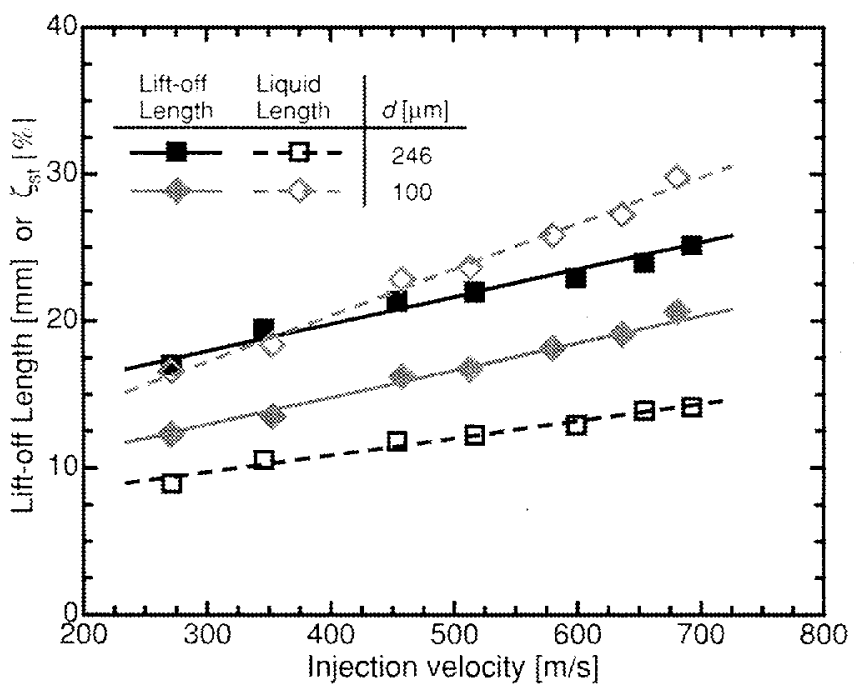

Figure 11. The estimated percent of stoichiometric air entrained upstream of the lift-off length $\left(\zeta_{s t}\right)$ based on Eq. (1) as a function of injection velocity for the $100 \mu \mathrm{m}$ and $246 \mu \mathrm{m}$ diameter orifices. Also shown are the lift-off lengths from Fig. 9. 


\section{Some Combined Effects of Injection Pressure and Orifice Diameter}

Figure 12 contains three schematics that show how the relative spatial relationship between various regions in the spray change with injection pressure and orifice diameter. The schematics are based on the lift-off length, the liquid length, and the air entrainment results presented Figs. 9-11, and on information in the literature on the structure of DI diesel sprays. The segment of the spray considered is the quasisteady, post-ignition, near-injector region established upstream of any wall interactions. The schematics are highly simplified and intended only for illustrating changes in the time-averaged, spatial relationship between various regions in a spray.

In each schematic, the dark gray region emanating from the injector tip at the bottom represents the region containing fuel droplets mixed with vaporized fuel and entrained air. (This region should not be interpreted as an "intact liquid core." Very little if any intact liquid core is believed to exist in high pressure DI diesel sprays.) The lighter gray region outside the fuel droplet containing region represents the region with vaporized fuel mixed with entrained air. The black curve emanating from the lift-off location in the downstream direction is the diffusion flame zone, which has been shown to exist near the periphery of the spray $[9,18]$. The vertical lined region in the vicinity of the lift-off length and liquid length represents the rich, distributed reaction zone suggested by the works of Chomiak and Karlsson [8] and Dec [9]. Since no direct measurements of combustion at the lift-off location or in the internal distributed reaction zone have been made, the location and shapes shown in the schematic for these regions should be considered to be speculative. The dotted region in the figure is the soot formation and growth region. Soot begins to form just downstream of the distributed reaction zone and evolves as the gases are transported downstream $[9,11]$. The cross-hatched band shown at the very downstream periphery of the spray, outside of the diffusion flame zone, represents a region of high temperature combustion products mixed with entrained air that appears in schlieren images of burning sprays, and grows inward as the spray penetrates farther downstream.

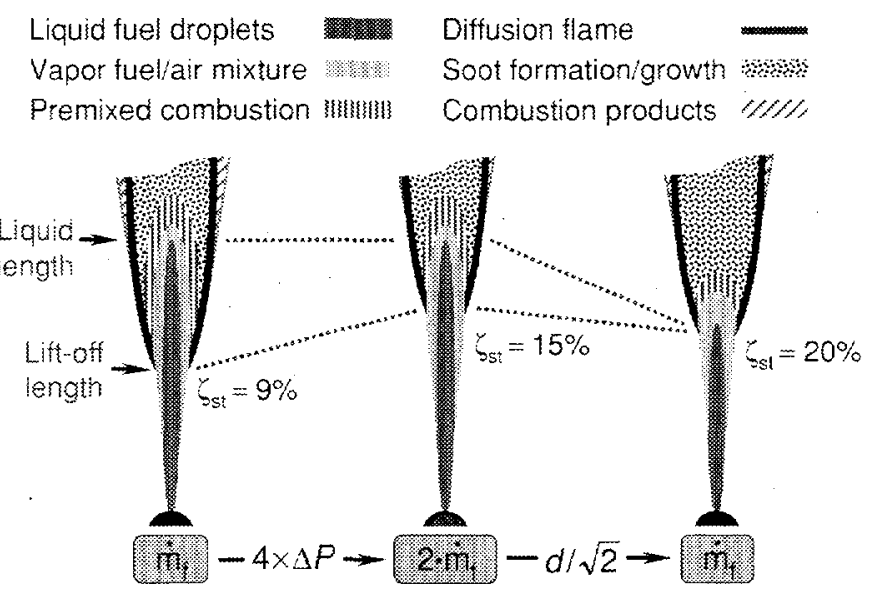

Figure 12. Three schematics showing how the spatial relationship between various regions in the spray change with injection pressure and orifice diameter. The schematic on the right is for an orifice pressure drop and orifice diameter of $40 \mathrm{MPa}$ and $250 \mu \mathrm{m}$. The middle schematic is for an orifice pressure drop and orifice diameter of $160 \mathrm{MPa}$ and $250 \mu \mathrm{m}$, i.e., the same diameter, but twice the fuel flow rate $\left(\dot{m}_{f}\right)$ as for the schematic on the left. The schematic on the right is for an orifice pressure drop and orifice diameter of $160 \mathrm{MPa}$ and $176 \mu \mathrm{m}$, which results in the same mass flow rate as for the schematic on the left. The conditions for the rightmost schematic are representative of current technology heavy-duty engines. 
The leftmost schematic in Fig. 12 is for a pressure drop across the injector orifice of $40 \mathrm{MPa}\left(\Delta P_{f}\right)$ and an orifice diameter of $250 \mu \mathrm{m}$. These injector conditions are representative of much older injector technology conditions. In the middle schematic, the effect of increasing the pressure drop across the orifice by a factor of four (to $160 \mathrm{MPa}$ ), while maintaining the orifice diameter at $250 \mu \mathrm{m}$, is shown. The higher pressure level is representative of injection pressures in current technology heavy-duty engines. The middle condition, however, has approximately twice the injection flow rate $\left(\dot{m}_{f}\right)$ as for the condition on the left. The schematic on the right shows the additional effect of decreasing the orifice diameter by a factor of $\sqrt{2}$ (to $176 \mu \mathrm{m}$ ) at the same time that the injection pressure is increased by a factor of four, thus maintaining the same injection rate as in the leftmost schematic. Both the injection pressure and orifice diameter for the schematic on the right are representative of injector conditions in current technology heavy-duty engines. The schematics are based on a gas density and temperature of $15 \mathrm{~kg} / \mathrm{m}^{3}$ and $1000 \mathrm{~K}$, which are representative of a moderate load engine condition.

The schematic on the left indicates that there is a significant quantity of unvaporized fuel at the lift-off location, and that $9 \%$ of the air required to burn the injected fuel is entrained by the lift-off length for the lower injection pressure, larger orifice diameter condition. The unvaporized fuel is confined to the central region of the spray based on images of the gas and liquid phases of sprays [e.g., 12]. Combustion downstream of the lift-off length surrounds this central region, most likely resulting in a significant length of spray with a vaporizing, relatively $\mathrm{cool}$, fuel rich core. For these conditions, there is a significant interaction between the initial combustion zones and the fuel vaporization process. Combustion will enhance the vaporization of any fuel not vaporized by the lift-off length and vaporization will cool the gases, and potentially increase the lift-off length due to temperature effects on flame speeds. This interaction provides a plausible explanation for the increase in lift-off length with increasing orifice diameter noted for diesel sprays in Fig. 10, but not for gas jets [e.g., 17]. As noted previously with Fig. 10, the interaction also implies that the non-combusting spray liquid length shown in the schematic is the maximum liquid length that could exist for the ambient gas conditions. The actual liquid length with combustion occurring is likely to be shorter than indicated in the leftmost schematic.

The middle schematic shows that increasing injection pressure begins to change the relationship between the regions of the spray containing liquid fuel and the combustion zones in the spray. The higher injection pressure of the middle schematic increases the lift-off length due to the higher injection velocities. The result is a $70 \%$ increase in air entrainment and greater fuel vaporization prior to the initial combustion zone (i.e., lift-off length). This in turn will result in more heat release in the distributed reaction zone and less interaction between the vaporization zones and the initial combustion zones. As with the schematic on the left, the actual liquid length in the middle schematic is likely to be shorter than the one shown, due to combustion effects on vaporization.

The rightmost schematic in Fig. 12 shows that changing the orifice diameter along with injection pressure, such that the mass flow rate remains unchanged, results in an even more dramatic change in the relationship between the liquid-phase fuel region and the combustion zones. In comparison to the schematic on the left, the fuel is largely vaporized prior to the liftoff length. This is due to more than twice as much hot air being entrained upstream of the lift-off length. The increased air entrainment prior to the lift-off length (over that in the leftmost schematic) is the result of an increase in the air entrainment rate relative to the fuel injection rate that occurs with a reduction in orifice diameter (as indicated by Eqs. (1) and (2)), coupled with a 
small net increase in lift-off length due to the combined orifice diameter and injection pressure effects on lift-off length.

The rightmost schematic suggests that there will be little direct interaction between the fuel vaporization and combustion processes for conditions typical of current technology heavyduty diesel engines, and that a significant quantity of premixed fuel and air will burn in the rich, distributed reaction zone. These observations are in agreement with the conceptual model for DI diesel combustion presented by Dec [9] for typical operating conditions in a heavy-duty DI diesel engine. The schematic on the right is very similar to the conceptual model presented by Dec [9] (albeit a more simplified version).

The trends in Fig. 12 indicate that diesel combustion has been evolving over time as injection pressures have been systematically increased, and to some extent orifice diameters reduced, to help meet emission regulations. The trends in injection pressure and orifice diameter have resulted in less direct interaction between the injected liquid-phase fuel and the combustion and emissions processes, and more air entrainment prior to combustion. This trend is likely to continue as injection pressures continue to be increased, especially if orifice diameters are also reduced to maintain flow rates as injection pressure and/or the number of orifices are increased. The net result will be diesel sprays that behave more and more like gas jets.

Another important consequence of the trends in Fig. 12 can be extracted by coupling them with the conceptual model of Dec [9]. In this conceptual model, soot begins forming downstream of a standing premixed flame. The conditions at the standing premixed flame will therefore have an impact on the soot formation processes in a diesel spray [11]. More air (i.e., oxygen) entrainment upstream of the lift-off length, for example, is likely to lead to less soot formation downstream of the standing premixed flame for the same reasons that oxygen addition via fuel bound oxygen has been noted to reduce the propensity for soot formation in Ref. 11 . Such an effect may be one of the factors contributing to the reduction in soot emissions noted with increased injection pressure, and suggests that oxygen, whether introduced via entrained air or bound in oxygenated fuels, may have equivalent effects on soot.

\section{Conclusions}

The effects of injection pressure and orifice diameter on the lift-off length of DI diesel sprays were investigated, and a natural light emission imaging technique for measuring lift-off length was discussed. The lift-off length experiments were conducted in a constant-volume combustion vessel under quiescent, heavy-duty DI diesel engine conditions. Ambient gas density and temperature conditions in the combustion vessel were characteristic of a moderate load engine condition. The fuel and injector used were a Phillips research grade \#2 diesel fuel and an electronically-controlled, common-rail fuel injector, respectively. Experiments were carried out for orifice diameters of $100 \mu \mathrm{m}$ and $246 \mu \mathrm{m}$ for injection pressures ranging from 40 to $185 \mathrm{MPa}$.

The results show that natural light emission at $310 \mathrm{~nm}$ provides an excellent marker of the upstream most location of combustion in a diesel spray (i.e., the lift-off length). Natural light emission at this wavelength is dominated by $\mathrm{OH}$ chemiluminescence formed by high temperature combustion at the lift-off length.

Lift-off lengths determined from images of natural light emission at $310 \mathrm{~nm}$ show that as injection pressure (i.e., injection velocity) increases or orifice diameter increases, the lift-off length increases. The lift-off length increase was about $50 \%$ for an increase in injection pressure from 40 to $185 \mathrm{MPa}$, and was linearly dependent on injection velocity, the same as noted for gas jets. The lift-off length increase with increasing orifice diameter was about $30 \%$ for an orifice 
diameter change from $100 \mu \mathrm{m}$ to $246 \mu \mathrm{m}$. This latter trend differs from the independence of liftoff length noted for gas jets.

An important overall observation was made by considering the lift-off length data in conjunction with liquid-phase fuel penetration and spray development data. The picture developed from the combined data suggests that DI diesel combustion and emission processes have been evolving over time as injection pressure and the number of orifices have been increased, and orifice diameters reduced to help meet emissions regulations. The evolution is the result of changes in the relationship and interaction between various processes occurring in a DI diesel spray in response to changes in injector parameters. The trends observed may ultimately help explain observed effects of injection pressure and orifice diameter on emissions. The trends observed are also trends that models being developed for DI diesel combustion must capture to accurately model diesel combustion and emissions processes.

\section{Acknowledgements}

Support for this research was provided by the U.S. Department of Energy, Office of Heavy-Duty Vehicle Technologies and Office of Advanced Automotive Technologies. The research was performed at the Combustion Research Facility, Sandia National Laboratories, Livermore, California. 


\section{References}

1. Rothrock AM, Waldron CD (1936) Effect of Nozzle Design on Fuel Spray and Flame Formation in a High-Speed Compression-Ignition Engine. T R No 561, NACA.

2. Shundoh S, Kakegawa T, Tsujimura K (1991) The Effect of Injection Parameters and Swirl on Diesel Combustion with High Pressure Fuel Injection. Transactions of the SAE, vol 100, sec 3, pp 793-805.

3. Verhoeven D, Vanhemelryck J, Baritaud T (1998) Macroscopic and Ignition Characteristics of High-Pressure Sprays of Single-Component Fuels. Transactions of the SAE, vol 107, sec 3, pp 1654-1668.

4. Winklhofer E, Fuchs H, Philipp H (1993) Diesel Spray Combustion - An Optical Imaging Analysis. Transactions of the SAE, vol 102, sec 3, pp 1154-1163.

5. Larsson A (1999) Optical Studies in a DI Diesel Engine. SAE1999-01-3650.

6. Pitts WM (1988) Assessment of Theories for the Behavior and Blowout of Lifted Turbulent Jet Diffusion Flames. Twenty-Second Symposium (International) on Combustion, The Combustion Institute, Pittsburgh, pp 809-816.

7. Peters N (2000) Turbulent Combustion. Cambridge University Press, New York.

8. Chomiak J, Karlsson A (1996) Flame Liftoff in Diesel Sprays. Twenty-Sixth Symposium (International) on Combustion, The Combustion Institute, Pittsburgh, pp 2557-2504.

9. Dec JE (1997) A Conceptual Model of DI Diesel Combustion Based on Laser-Sheet Imaging. Transactions of the SAE, vol 106, sec 3, pp 1319-1348.

10. Siebers DL (1999) Scaling Liquid-Phase Fuel Penetration in Diesel Sprays Based on Mixing-Limited Vaporization. SAE1999-01-0528.

11. Flynn PF, Durrett RP, Hunter GL, zur Loye AO, Akinyemi OC, Dec JE, Westbrook CK (1999) Diesel Combustion: An Integrated View Combining Laser Diagnostics, Chemical Kinetics, and Empirical Validation. SAE1999-01-0509.

12. Siebers DL (1998) Liquid-Phase Fuel Penetration in Diesel Sprays. Transactions of the SAE, vol 107, sec 3, pp 1205-1227.

13. Naber JD, Siebers DL (1996) Effects of Gas Density and Vaporization on Penetration and Dispersion of Diesel Sprays. Transactions of the SAE, vol 105, sec 3, pp 82-111.

14. Siebers DL (1985) Ignition Delay Characteristics of Alternative Diesel Fuels: Implications on Cetane Number. Transactions of the SAE, vol 94, sec 7, pp 673-686.

15. Oren DC, Wahiduzzaman S, Ferguson CR (1984) A Diesel Combustion Bomb: Proof of Concept. Transactions of the SAE, vol 93, sec 5, pp 945-960.

16. Durrett RP, Oren DC, Ferguson CR (1987) A Multidimensional Data Set for Diesel Combustion Model Validation: I-Initial Conditions, Pressure History and Spray Shapes. SAE 872087.

17. Kalghatgi GT (1984) Lift-Off Heights and Visible Lengths of Vertical Turbulent Diffusion Flames in Still Air. Combustion Science and Technology, vol 41, pp 17-29. 
18. Kosaka H, Nishigaki T, Kamimoto T, Sano T, Matsutani A, Harada S (1996)

Simultaneous 2-D Imaging of OH Radicals and Soot in a Diesel Flame by Laser Sheet Techniques. Transactions of the SAE, vol 105, sec 3, pp 1184-1195.

19. Dec JE, Espey C (1998) Chemiluminescence Imaging of Autoignition in a DI Diesel Engine. SAE982685.

20. Gaydon AG (1974) The Spectroscopy of Flames. Chapman and Hall Ltd., London. 


\section{DISTRIBUTION:}

Caterpillar Inc.

Attn: Rey Agama

Technical Center, Bldg. L

P.O. Box 1875

Peoria, Illinois 61656-1875

Caterpillar Inc.

Attn: John M. Clarke

Technical Center, Bldg. L

P.O. Box 1875

Peoria, Illinois 61656-1875

Caterpillar, Inc.

Attn: William L. Brown

Engine Division Engineering

P.O. Box 0610

Mossville, IL 61552-0610

Caterpillar, Inc.

Attn: Ashok Chanda

P.O. Box 1875

Peoria, IL 61656-1875

University of Wisconsin

Attn: Professor Rolf Reitz

123 Engineering Research Bldg.

1500 Engineering Drive

Madison, Wisconsin 53706

University of Wisconsin-Madison

Attn: Professor David E. Foster

Dept. of Mechanical Engineering

113 Engineering Research Building

1500 Johnson Drive

Madison, WI 53706

Chrysler Corporation

Attn: Thomas W. Asmus

CIMS 482-01-19

800 Chrysler Dr., East

Auburn Hills, MI 48326
Cummins Engine Company

Attn: Wayne A. Eckerle

Mail Code 18210

P.O. Box 3005

Columbus, IN 47202-3005

Cummins Engine Co.

Attn: Patrick F. Flynn

Mail Code 50181

P.O. Box 3005

Columbus, IN 47202-3005

Cummins Engine Co.

Attn: Axel O. zur Loye

Mail Cole 50180

P.O. Box 3005

Columbus, IN 47202-3005

Cummins Engine Co.

Attn: Gary L. Hunter

Mail Cole 50180

P.O. Box 3005

Columbus, IN 47202-3005

Cummins Engine Co.

Attn: Roy J. Primus

Mail Cole 50180

P.O. Box 3005

Columbus, IN 47202-3005

Cummins Engine Co.

Attn: Russell Durrett

Mail Cole 50180

P.O. Box 3005

Columbus, IN 47202-3005

Detroit Diesel Corp.

Attn: Nabil S. Hakim

13400 Outer Drive, West

Detroit, Michigan 48239-4001 
DISTRIBUTION: (continued)

Detroit Diesel Corp.

Attn: Craig Savonen

13400 Outer Drive, West

Detroit, MI 48239-4001

Detroit Diesel Corp.

Attn: John (Jun) Xin

13400 Outer Drive, West

Speed Code: A06

Detroit, MI 48239-4001

Lubrizol Corporation

Attn: Daniel Daly

29400 Lakeland Boulevard

Wickliffe, Ohio 44092-2298

Ethyl Petroleum Additives, Inc.

Attn: Allen Aradi

500 Spring Street

P.O. Box 2158

Richmond, VA 23218-2158

Ford Research Laboratory

Attn: Richard Anderson

Room 3622B, SRL

P.O. Box 2053

Dearborn, MI 48121-2053

General Motors Research

Attn: Sherif El Tahry

30500 Mound Road

Warren, MI 48090-9055

General Motors Research

Attn: David L. Harrington

30500 Mound Road 1-6

P.O. Box 9055

Warren, MI 48090-9055

General Motors Research

Attn: Roger Krieger

30500 Mound Road

P.O. Box 9055

Warren, MI 48090-9055
General Motors Research

Attn: John Pinson

Thermosciences Dept., 254 Reb, 1-6

30500 Mound Road

Warren, MI 48090-9055

Southwest Research Institute

Attn: Thomas W. Ryan III

6220 Culebra Road

P.O. Drawer 28510

San Antonio, TX 78228-0510

John Deere PEC

Attn: Arnold DeJoode

Engine Engineering

Gate 3, Ridgeway Ave.

Waterloo, Iowa 50701

Los Alamos National Laboratory

Attn: T. Daniel Butler

Theoretical Division, Group T-3

Mail Stop B-216

Los Alamos, NM 87545

Los Alamos National Laboratory

Attn: Peter O'Rourke

Theoretical Division, Group T-3

Mail Stop B-216

Los Alamos, NM 87545

Princeton University

Attn: Philip Felton

Mechanical Engineering Dept.

Prospect St., Room G02

Princeton, NJ 08544

Massachusetts Institute of Technology

Attn: Professor John B. Heywood

Mechanical Engineering

77 Massachusetts Avenue

Cambridge, Massachusetts 02319

Navistar International Transportation

Corporation

Attn: Laura Ricart

10400 W. North Ave.

Melrose Park, IL 60160 
DISTRIBUTION: (continued)

Pennsylvania State University

Attn: Professor Thomas A. Litzinger

Department of Mechanical Engineering

202B Rider II Building

University Park, Pennsylvania 16802

Pennsylvania State University

Attn: Professor Domenic A. Santavicca

Dept. of Mechanical Engineering

132 Research Building East - Bigler Rd.

University Park, PA 16802

Purdue University

Attn: Professor John Abraham

School of Mechanical Engineering

1003 Chaffee Hall

West Lafayette, IN 47907-1288

Purdue University

Attn: Professor J. P. Gore

School of Mechanical Engineering

1003 Chaffee Hall

West Lafayette, IN 47907-1003

U.S. Army Tank-Automotive Command Attn: Walter Bryzik

AMSTA-R

Tank-Automotive RDE Center

Warren Michigan 48397-5000
U.S. Department of Energy

Attn: James Eberhardt

OTT, EE-33

1000 Independence Ave.

Washington, D.C. 20585

U.S. Department of Energy

Attn: Kathi Epping

OTT, EE-32

1000 Independence Ave.

Washington, D.C. 20585-0121

U.S. Department of Energy

Attn: John W. Fairbanks

OTT, EE-33

1000 Independence Ave.

Washington, D.C. 20585-0121

U.S. Department of Energy

Attn: Steve Goguen

OTT/EE-33

1000 Independence Avenue, SW

Washington DC 20585

U.S. Department of Energy

Attn: Kenneth Howden

OTT, EE-32

1000 Independence Ave.

Washington, D.C. 20585-0121

U.S. Department of Energy

Attn: Gurpreet Singh

OTT, EE-33

1000 Independence Ave.

Washington, D.C. 20585-0121 


\section{DISTRIBUTION: (continued)}

$1 \quad$ MS 9054

$30 \quad$ MS 9053

$1 \quad$ MS 9053

$1 \quad$ MS 9053

$3 \quad$ MS 9018

$1 \quad$ MS 0899

$1 \quad$ MS 9021

$1 \quad$ MS 9021
W. McLean, 8300

Attn: CRF Managers

D. Siebers, 8362

R. Carling, 8362

J. Keller, 8362

Central Technical Files, 8940-2

Technical Library, 4916

Technical Communications Department, 8528/

Technical Library, MS 0899, 4916

Technical Communications Department, 8528 For DOE/OSTI 